\title{
Late arrhythmia in adults with the Mustard procedure for transposition of great arteries: a surrogate marker for right ventricular dysfunction?
}

\author{
M A Gatzoulis, J Walters, P R McLaughlin, N Merchant, G D Webb, P Liu
}

\begin{abstract}
Objective-To examine the relation between ventricular dysfunction and late clinical arrhythmia in adults who underwent the Mustard procedure for transposition of the great arteries.

Design-Observational study based on periodic outpatient assessment of biventricular function. Setting-Tertiary referral centre.

Interventions-Analysis of data from 12 lead ECGs, echocardiography, exercise radionuclide ventriculography, and magnetic resonance imaging.

Main outcome measures-Clinical outcome and late onset clinical arrhythmia during follow up. ECG and ventricular function indices obtained before arrhythmia onset were used for analysis.

Results-51 patients (mean (SD) age 25.7 (5.0) years) fulfilled entry criteria at a mean of 23.4 (4.0) years after the Mustard procedure. Late arrhythmia occurred in $11(22 \%)$ : sustained atrial flutter/fibrillation in 10, ventricular tachycardia in one. Compared with patients who remained arrhythmia free, patients with arrhythmia had longer QRS (129 (26) v 112 (16) ms, p = 0.01), greater QT dispersion (107 (28) v $51(24) \mathrm{ms}, \mathrm{p}<0.001$ ), and increased ratio of right to left ventricular end diastolic diameter (2.4 (0.9) $v 1.7(0.7), \mathrm{p}=0.02)$, but no difference in wall thickness. Systemic ejection fraction was also reduced in the arrhythmia subgroup (at rest: 34.1 (13)\% $v 47(16) \%, \mathrm{p}=0.04$; during exercise: $37.8(12) \%$ v $52(17) \%, \mathrm{p}=0.03)$. QRS duration correlated with right ventricular end diastolic diameter $(r=0.59, \mathrm{p}<0.001)$, suggesting a possible mechano-electric relation after the Mustard procedure. QT dispersion was the only predictor of clinical arrhythmia in multivariate analysis.

Conclusions-Impaired ventricular function in adults with the Mustard procedure for transposition of the great arteries relates to clinical arrhythmia. Late atrial flutter/fibrillation may be a surrogate marker for ventricular dysfunction, and these patients may also be at risk of ventricular tachycardia.

(Heart 2000;84:409-415)
\end{abstract}

Keywords: congenital heart disease; transposition of great vessels; arrhythmia; radionuclide ventriculography

Clinical arrhythmia and sudden cardiac death are late complications in patients with transposition of the great arteries who have undergone previous atrial switch procedures (Mustard or Senning). ${ }^{1-3}$ Systemic ventricular dysfunction has been postulated as a possible cause for both these complications. ${ }^{12}$ However, there are no studies specifically addressing the potential relation of clinical arrhythmia and ventricular function in this population. Furthermore, the fate of the right ventricle supporting the systemic circulation for a lifetime remains a cause of concern. ${ }^{45}$ Early identification of patients at risk, therefore, may allow the preservation or restoration of ventricular function by medical or surgical interventions. ${ }^{6-8}$

The arterial switch procedure, ${ }^{910}$ which overcomes the shortfalls of a systemic right ventricle, has superseded the Mustard and Senning operations in most places of the world. However, ever increasing numbers of patients with previous atrial switch procedures are now entering adulthood. ${ }^{11}$ Our aim in this study was to examine the possible relation between biventricular function and late occurrence of clinical arrhythmia in this emerging adult population.

\section{Methods}

PATIENTS

All adult patients with the Mustard procedure for transposition of great arteries who are registered with the University of Toronto Congenital Cardiac Centre for Adults (UTCCCA) and have been undergoing periodic outpatient cardiac assessment were identified from its database. The study population comprises patients who underwent full assessment of ventricular function by exercise radionuclide ventriculography and ventricular size by magnetic resonance imaging within the preceding 12 months from the onset of arrhythmia, or at the most recent follow up (for the arrhythmiafree patients) at the UTCCCA. Patients with early arrhythmia occurring before their transfer to UTCCCA were not included. Clinical assessment and standard 12 lead ECGs, 24 hour Holter recordings, chest $x$ rays, and transthoracic echocardiograms routinely performed during corresponding clinic reviews were included in the analysis.

\section{CLINICAL DATA}

Demographic, clinical, and surgical details were obtained from the UTCCCA database and the patients' records. Patients requiring 
additional surgery for ventricular septal defect closure, repair of double outlet right ventricular connection, relief of pulmonary stenosis, or combinations of these were characterised as "complex". The arrhythmia subset comprised patients with documented sustained atrial flutter/fibrillation or ventricular tachycardia and associated symptoms during follow up at UTCCCA. Patients with junctional rhythm only or non-sustained episodes of atrial or ventricular arrhythmia on Holter monitoring were not included in the arrhythmia subgroup. When functional capacity was assessed more than once, data from the most recent entry or the last full assessment before the onset of arrhythmia were used for the analysis. Finally, we did not differentiate between chronic or paroxysmal atrial tachyarrhythmia.

Periodic assessment of ventricular function with radionuclide ventriculography and magnetic resonance imaging was approved by The Toronto Hospital human ethics committee.

ELECTROCARDIOGRAPHY, RADIOGRAPHY, AND ECHOCARDIOGRAPHY

The predominant underlying rhythm and the presence of sustained atrial or ventricular tachycardia were determined from 12 lead ECGs, Holter recordings, and ECG strips. ECG measurements were made manually by a blinded single investigator from 12 lead sinus or junctional ECGs corresponding to the time of full cardiac assessment, and before the onset of arrhythmia. ${ }^{12} 13$

Cardiothoracic ratio was obtained from posteroanterior chest $x$ rays in the standard manner.

All patients had routine transthoracic echocardiograms within three months of the exercise radionuclide ventriculography and magnetic resonance imaging. Systemic ventricular dysfunction and tricuspid regurgitation were assessed (grade: I-II $=$ absent or mild, III = moderate, IV = severe) by $M$ mode (one dimensional) echocardiography, pulsed wave, and colour flow Doppler analysis. Available haemodynamic data from recent cardiac catheterisations were also recorded. Left ventricular hypertension was considered to be present when left ventricular systolic pressure derived from continuous wave Doppler estimation or cardiac catheterisation was $\geqslant 60 \mathrm{~mm} \mathrm{Hg}$.

MAGNETIC RESONANCE IMAGING

Magnetic resonance imaging acquisition involved an initial coronal ECG triggered spin echo sequence to obtain the optimal angle for long axis, short axis, and transaxial "four chamber" views of the heart. ${ }^{14}$ Images were acquired as $T_{1}$ weighted spin echo with an applied triggered to assure a diastolic acquisition with the following variables: $T R=1 \mathrm{RR}$ interval, $\mathrm{TE}=20 \mathrm{~ms}, \quad \mathrm{FOV}=24 \mathrm{~cm}$, $\mathrm{NEX}=2$, matrix $256 \times 192$, and superior/ inferior saturation band. Images were transferred to an independent computer work station (Advantage Windows Work Station) for analysis. Two measurements of right and left ventricular end diastolic diameters (RVEDD, LVEDD) were made at mid-ventricular level in the transaxial view, and their average was used for the analysis. Right ventricular free wall (RVWT), interventricular septal wall (IVWT), and left posterior wall thickness (LVWT) were also measured at mid-ventricular level in the transaxial view in duplicate (end diastole), and their average was recorded. Interobserver and intraobserver variability was examined by repeat measurements in a subset of randomly chosen magnetic resonance imaging samples.

\section{CARDIOPULMONARY EXERCISE TESTING}

Graded exercise testing using an electronically braked cycle ergometer was performed in the semiupright position to assess cardiopulmonary status. The patient's heart rate and rhythm were continuously monitored with a three lead ECG. Blood pressure was measured by an automated cuff at one minute intervals. Breath by breath collection of expired gases was obtained using a metabolic cart (Sensormedics 4400); with the oxygen and carbon dioxide measurement results reported as 15 second averages. After a one minute warm up phase against minimal resistance, the work load increased continuously by an average of $200 \mathrm{kpm}$ every three minutes and the exercise continued until a symptom limited maximum was reached. The average duration of exercise is in the range of 6-10 minutes for this group of Mustard patients. The ventilatory anaerobic threshold was determined by analysis of the relation between ventilation and oxygen consumption, confirmed by examination of the ventilation equivalent of $\mathrm{CO}_{2}$ output over oxygen consumption $\left(\dot{\mathrm{V} E \mathrm{CO}_{2}} / \dot{\mathrm{VEO}}_{2}\right)$.

\section{RADIONUCLIDE VENTRICULOGRAPHY}

Before initial exercise testing patients received $25 \mathrm{mCi}$ of technetium-99m pertechnetate for red blood cell labelling, using a standard modified in vivo technique. ${ }^{15}$ Gated radionuclide ventriculography (Apex 409 Elscint camera) was performed at rest in anterior, lateral, and oblique views. The right ventricle was studied in the projection with the most septal separation between right and left ventricles. To obtain exercise ventriculography, the patient underwent a graded exercise protocol with warm up of one minute at $200 \mathrm{kpm}$, after which the exercise load was increased to $70 \%$ of the patient's previous maximum work load. The patients sustained exercise at this level for one minute to attain steady state and an additional two minutes for nuclear image acquisition, obtained in the previously determined best septal view. Right and left ejection fractions, using background subtraction from an adjacent pulmonary area, were then analysed by two experienced independent observers with commercially available software, after which the results were averaged.

Previously published data on normal controls from our laboratory ${ }^{16}$ on systemic ventricular ejection fraction and cardiopulmonary exercise testing were employed for comparison with the Mustard patients. 
STATISTICAL ANALYSIS

The SPSS for Windows Software (version 7.5) was used for data analysis. Descriptive data for continuous variables are presented as mean (SD) unless indicated otherwise. Comparisons between the Mustard and control groups and within the Mustard group between the arrhythmia subset and the remainder were made with the $\chi^{2}$ test, Fisher's exact test, or Student's $t$ test where appropriate. Linear regression analysis between ventricular dimensions/wall thickness and ECG indices was performed. Univariate analysis of predictors of clinical arrhythmia was performed using Cox's proportional hazard model. Collinearity between variables was examined; highly correlated variables (correlation coefficient $>0.70$ ) were combined into a composite variable. Univariate predictors with a significant level of $<0.10$ were entered into a multivariate Cox proportional hazard model using a stepwise backwards elimination algorithm. ${ }^{17}$ Two tailed significance level was set at the value of $\mathrm{p}<0.05$.

\section{Results}

CLINICAL DATA

Fifty one patients ( 35 male, 16 female), fully assessed at a mean age of 25.7 (5.1) years, fulfilled criteria to enter the study. All 51 patients underwent the Mustard procedure at the Hospital for Sick Children at a mean age of 2.4 (2.0) years (range 0.4-9.6 years). Total follow up time was 23.4 (3.9) years (range 18-33 years). Patients were generally referred at the age of 18 to UTCCCA, where they have been followed for a mean of 5.4 (3.7) years. Fifteen patients (29\%) required "complex" Mustard repair involving ventricular septal defect closure $(\mathrm{n}=13$, with double outlet right ventricular connection in three) and/or relief of left ventricular outflow tract obstruction $(n=6)$. At the time of radionuclide ventriculography and magnetic resonance imaging studies and before the onset of clinical arrhythmia, 44 of the patients $(86 \%)$ were in New York Heart Association functional class I-II. The remainder were in class III-IV.

Table 1 Electrocardiographic, radiographic, echocardiographic, and magnetic resonance imaging data (51 Mustard patients)

\begin{tabular}{llll}
\hline RR interval, rest (ms) & $920(254)$ & & \\
PR interval (ms) & $181(35)$ & \\
Superior QRS axis $\left(0^{\circ}\right.$ to $\left.+180^{\circ}\right)$ & $11(21.6 \%)$ & \\
QRS duration max (ms) & $116(20)$ & \\
QT interval (ms) & $470(54)$ & & \\
QT dispersion (ms) & $62(34)$ & & \\
U wave (biphasic or >50\% of T wave) & $8(15.7 \%)$ & & \\
CTR & $0.51(0.07)$ & & \\
Echocardiography & & & \\
Severity & $I-I I$ & & \\
RV dysfunction, rest & $23(45 \%)$ & & \\
Tricuspid regurgitation & $34(66.7 \%)$ & & \\
Magnetic resonance imaging & & & \\
RVEDD (mm) & $41.2(8.1)$ & \\
LVEDD (mm) & $25.6(8.7)$ & & \\
Ratio of RVEDD to LVEDD & $1.85(0.8)$ & \\
RV free wall thickness (mm) & $12.8(3.3)$ & \\
LV posterior wall thickness (mm) & $8.4(2.3)$ & \\
Ratio of RV to LV wall thickness & $1.6(0.5)$ & \\
IVS thickness (mm) & $9.8(2.9)$ & & \\
\end{tabular}

Values are mean (SD) or $\mathrm{n}(\%)$.

CTR, cardiothoracic ratio; I-II, absent or mild; III, moderate; IV, severe; IVS, intraventricular septum; LV, left ventricular; LVEDD, left ventricular end diastolic diameter; RV, right ventricular; RVEDD, right ventricular end diastolic diameter.
The 51 patients reported in this study are a subset of a larger cohort of 122 Mustard patients who are registered with the UTCCCA. There was no difference between the two groups for sex (73 male, 49 female, $p=0.23$ ), age at Mustard procedure $(2.13$ (2.36) years, $\mathrm{p}=0.44)$, length of follow up (23.79 (4.2) years, $\mathrm{p}=0.54)$, or prevalence of late arrhythmia $(19.7 \%, p=0.63)$, suggesting that there was no selection bias.

\section{ELECTROCARDIOGRAPHY AND}

ECHOCARDIOGRAPHY

Junctional rhythm was the predominant rhythm in 11 patients. Four patients had received a pacemaker for sick sinus syndrome $(\mathrm{n}=3)$ and complete atrioventricular block $(n=1)$; none of these had a history of tachyarrhythmia. These four patients, and the nine patients with junctional rhythm who remained free of atrial flutter/fibrillation and ventricular tachycardia, were assigned to the nonarrhythmia subgroup for the purpose of statistical analysis. Electrocardiographic, radiographic, and echocardiographic data are shown in table 1. Maximum QRS duration and QT dispersion was significantly greater in the arrhythmia subgroup than in the arrhythmiafree subgroup (fig 1).

Eight patients had one or more residual haemodynamic lesions: intra-atrial baffle leak $(\mathrm{n}=3)$, left ventricular hypertension (systolic pressure $\geqslant 60 \mathrm{~mm} \mathrm{Hg}$ because of left ventricular outflow tract obstruction $(n=3)$, pulmonary hypertension $(n=2)$ ), and small residual ventricular septal defect $(n=1)$.

\section{MAGNETIC RESONANCE IMAGING}

Magnetic resonance imaging data from the 51 patients are shown in table 1 . The ratio of right to left ventricular end diastolic diameter was significantly greater in the arrhythmia patients when compared with the remainder, suggesting relative right ventricular enlargement (fig 1). By contrast, no difference was seen in right to left ventricular wall thickness between the arrhythmia subset and the remainder of the Mustard patients. When absolute measurements and ratios of biventricular diameter and wall thickness were tested against ECG conduction parameters for correlates, there was a significant correlation between maximum QRS duration and right ventricular end diastolic dimension $(r=0.59, \mathrm{p}<0.001$, fig 2$)$, but not right ventricular wall thickness.

Repeated measurements of right and left ventricular end diastolic dimension and wall thickness in six samples randomly chosen from the Mustard cohort were performed twice by two blinded observers. The percentage differences ranged from $0-7 \%$ for within observer variability, and $1-11 \%$ for between observer variability.

RADIONUCLIDE VENTRICULOGRAPHY AND CARDIOPULMONARY EXERCISE TESTING

Radionuclide ventriculography and cardiopulmonary testing was performed in all 51 subjects. Forty three patients ended the exercise test because of fatigue, the remainder 

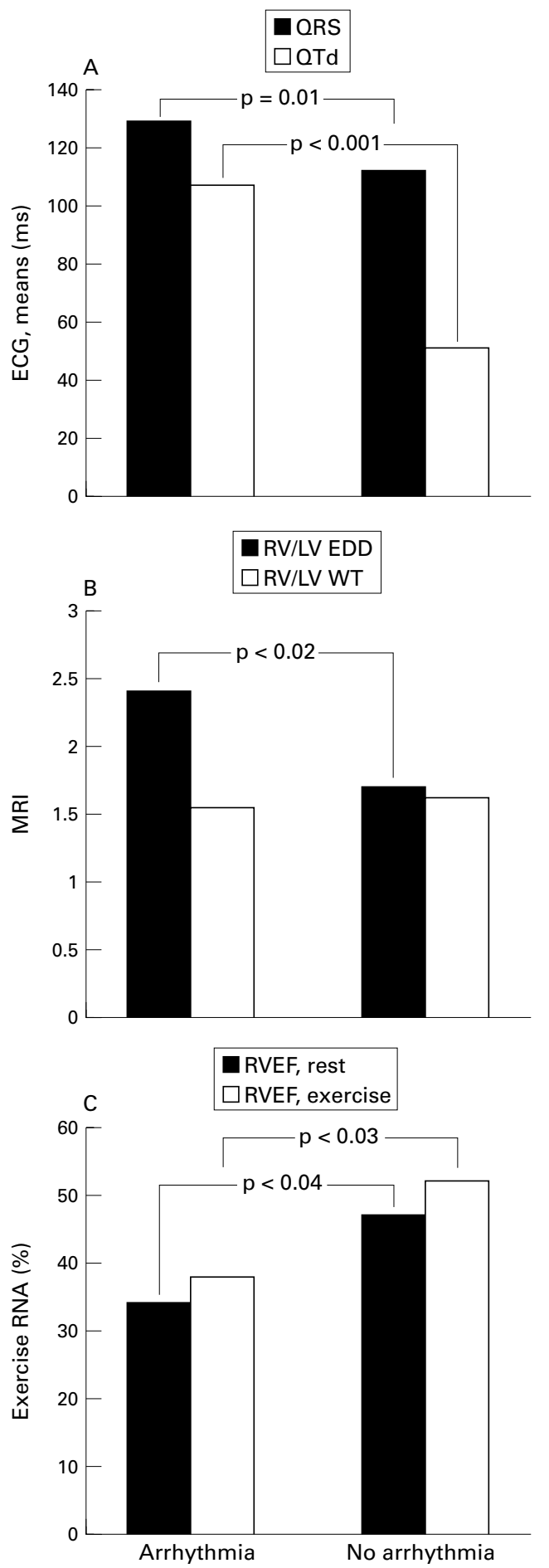

Figure 1 (A) Maximum $Q R S$ duration and $Q T$ dispersion from surface ECG measured manually before the onset of arrhythmia and drug treatment. (B) Means of ratios of right to left ventricular end diastolic diameter and wall thickness on magnetic resonance imaging between the 11 patients with arrhythmia and the remaining 40 arrhythmia-free patients (transaxial views at

mid-ventricular frames, average of two measurements).

(C) Ejection fraction of the systemic right ventricle by exercise radionuclide ventriculography. MRI, magnetic resonance imaging; $R N A$, radionuclide ventriculography; $R V E F$, right ventricular ejection fraction; RV/LV EDD, right to left ventricular end diastolic diameter; RV/LV WT, right to left ventricular wall thickness (end diastole).

because of exertional dyspnoea. Systemic (right ventricular) function in the Mustard patients was significantly reduced compared

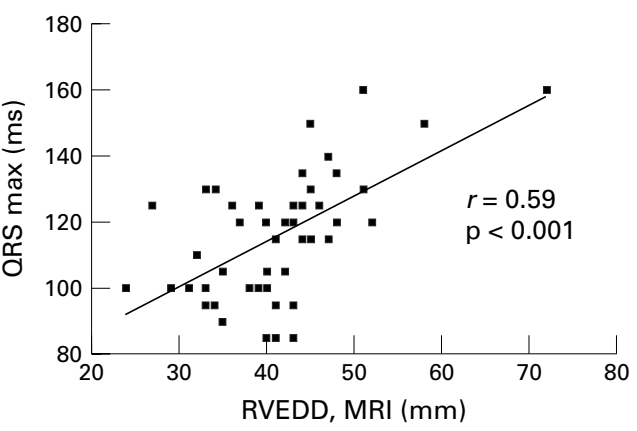

Figure 2 Linear correlation between maximum $Q R S$ duration (measured manually from surface ECG before onset of arrhythmia) and right ventricular end diastolic diameter from magnetic resonance imaging (RVEDD, $M R I)$ (transaxial views at mid-ventricular frames), suggesting a possible mechano-electric interaction in adult patients after the Mustard procedure.

with normal healthy controls (ejection fraction at rest $44.5(1.0) \%$ v $58(7) \%, \mathrm{p}=0.027$, and during exercise 49.3 (1.0)\% v 69.5 (8.0)\%, $\mathrm{p}=0.002$ ). Heart rate response to exercise was blunted in the Mustard patients (140 (26) $v$ 178 (19) beats/min in the controls, $\mathrm{p}<0.001)$. Cardiopulmonary exercise performance was also impaired in the Mustard cohort compared with the healthy controls (anaerobic threshold 11.1 (4.0) v 23.6 (5.0) $\mathrm{ml} / \mathrm{kg} / \mathrm{min}, \mathrm{p}<0.001$; maximum oxygen uptake $17.5(6.0) v$ 42 (10) $\mathrm{ml} / \mathrm{kg} / \mathrm{min}, \mathrm{p}<0.001$, respectively). Within the Mustard patients, those who subsequently developed clinical arrhythmia had significantly reduced right ventricular ejection fraction, both at rest and during exercise, compared with the arrhythmia-free patients by the end of the study (fig 1).

ARRHYTHMIA

Eleven patients (22\%) had documented, sustained atrial flutter/fibrillation $(\mathrm{n}=10)$ and ventricular tachycardia $(n=1)$ during their follow up at the UTCCCA at a mean age of 25.6 (4.8) years. Five of them presented with palpitations and exertional dyspnoea, four with presyncope or syncope, and two with congestive heart failure. The demographic, surgical, and haemodynamic details of these 11 patients with clinical arrhythmia are shown in table 2 and compared with the remainder of the Mustard cohort. All but two patients required electrical cardioversion. Three of them have been considered for the double switch conversion. One patient with ventricular tachycardia was too unstable for left ventricular retraining with pulmonary arterial banding ${ }^{6}$ and died during heart transplantation (myocardial standstill). The remaining eight patients have been managed medically with antiarrhythmic drugs or angiotensin converting enzyme (ACE) inhibition.

PREDICTORS OF LATE CLINICAL ARRHYTHMIA

Univariate analysis of potential predictors of arrhythmia is shown in table 3 . In this cohort of adults with Mustard procedure for transposition of great arteries, multivariate analysis showed QT dispersion to be the only independent predictor of late clinical arrhythmia. 
Table 2 Comparison between patients with clinical arrhythmia versus the remainder (Mustard patients)

\begin{tabular}{|c|c|c|c|}
\hline & $\begin{array}{l}\text { Arrhythmia } \\
(n=11)\end{array}$ & $\begin{array}{l}\text { No arrhythmia } \\
(n=40)\end{array}$ & $p$ Value \\
\hline Age, repair (years) & $2.16(0.96)$ & $2.5(2.2)$ & 0.6 \\
\hline Male/female & $7 / 4$ & $28 / 12$ & 0.7 \\
\hline "Complex" repair & 4 & 11 & 0.7 \\
\hline FU length (years) & $23.6(4.5)$ & $23.3(3.7)$ & 0.8 \\
\hline NYHA $\geqslant$ III & 3 & 4 & 0.1 \\
\hline \multicolumn{4}{|l|}{ ECG } \\
\hline Junctional rhythm & 2 & 9 & 0.9 \\
\hline Superior $\mathrm{QRS}$ axis & 5 & 6 & 0.03 \\
\hline $\mathrm{RR}$ interval (ms) & $985(319)$ & $912(238)$ & 0.4 \\
\hline QRS duration max (ms) & $129(26)$ & $112(16)$ & 0.01 \\
\hline QT interval (ms) & $519(55)$ & $458(47)$ & 0.001 \\
\hline QT dispersion (ms) & $107(28)$ & $51(24)$ & $<0.001$ \\
\hline U waves & 4 & 4 & 0.04 \\
\hline \multicolumn{4}{|l|}{ Echocardiography } \\
\hline RV dysfunction $\geqslant$ III & 7 & 21 & 0.5 \\
\hline $\mathrm{TR} \geqslant$ moderate & 5 & 10 & 0.2 \\
\hline $\mathrm{RVEF} \geqslant \mathrm{III}$ and $\mathrm{TR} \geqslant \bmod$ & 5 & 6 & 0.03 \\
\hline LV hypertension $\star$ & 3 & 2 & 0.06 \\
\hline \multicolumn{4}{|l|}{ Magnetic resonance imaging } \\
\hline RVEDD (mm) & $43.6(9.6)$ & $40.5(7.6)$ & 0.3 \\
\hline LVEDD (mm) & $20.3(6.8)$ & $27(8.8)$ & 0.03 \\
\hline RVEDD/LVEDD ratio & $2.4(0.9)$ & $1.7(0.7)$ & 0.02 \\
\hline RV free wall thickness (mm) & $11.9(2.1)$ & $13(3.5)$ & 0.4 \\
\hline LV wall thickness (mm) & $8.2(2.0)$ & $8.6(2.4)$ & 0.7 \\
\hline $\mathrm{RV} / \mathrm{LV}$ wall thickness ratio & $1.55(0.5)$ & $1.61(0.6)$ & 0.8 \\
\hline IVS thickness (mm) & $9.5(1.8)$ & $9.8(3.1)$ & 0.9 \\
\hline \multicolumn{4}{|c|}{$\begin{array}{l}\text { Radionuclide ventriculography } \\
\text { and cardiopulmonary exercise testing }\end{array}$} \\
\hline Heart rate, rest (beats/min) & $68.6(10.0)$ & $71.3(13.7)$ & 0.50 \\
\hline Heart rate, ex (beats/min) & $132(26)$ & $142(26)$ & 0.30 \\
\hline $\mathrm{BP}$ systolic, rest (mm Hg) & $116(17)$ & $119(14)$ & 0.30 \\
\hline $\mathrm{BP}$ systolic, ex $(\mathrm{mm} \mathrm{Hg})$ & $152(20)$ & $161(28)$ & 0.50 \\
\hline RVEF, rest (\%) & $34.1(13.0)$ & $47.0(16.0)$ & 0.04 \\
\hline RVEF, ex (\%) & $37.8(12.0)$ & $52.0(17.4)$ & 0.03 \\
\hline LVEF, rest (\%) & $52.6(12.0)$ & $55.2(12.0)$ & 0.50 \\
\hline LVEF, ex (\%) & $63.0(18.0)$ & $63.0(13.5)$ & 0.90 \\
\hline Exercise time ( $\mathrm{min}$ ) & $6.0(2.0)$ & $7.2(2.4)$ & 0.06 \\
\hline $\mathrm{AT}(\mathrm{ml} / \mathrm{kg} / \mathrm{min})$ & $10.2(3.0)$ & $11.4(3.8)$ & 0.40 \\
\hline$\dot{\mathrm{V}_{2}} \max (\mathrm{ml} / \mathrm{kg} / \mathrm{min})$ & $15.2(5.0)$ & $18.3(6.0)$ & 0.10 \\
\hline Work load (kpm) & $604(123)$ & $725(214)$ & 0.08 \\
\hline
\end{tabular}

Values are $\mathrm{n}$ or mean (SD)

*Patients with more than mild left ventricular hypertension (left ventricular systolic pressure from cardiac catheterisation and/or continuous wave Doppler $>60 \mathrm{~mm} \mathrm{Hg}$ ) owing to left ventricular outflow tract obstruction $(n=3)$ or pulmonary hypertension $(n=2)$.

AT, anaerobic threshold; BP, blood pressure; FU, follow up; IVS, intraventricular septal; LV, left ventricular; LVEDD, left ventricular end diastolic diameter; LVEF, left ventricular ejection fraction; RV, right ventricular; RVEDD, right ventricular end diastolic diameter; RVEF, right ventricular ejection fraction; TR, tricuspid regurgitation; $\dot{\mathrm{V}}_{2}$ max, maximum oxygen uptake.

Table 3 Predictors of late clinical arrhythmia in adults with the Mustard procedure for transposition of the great arteries

\begin{tabular}{|c|c|c|}
\hline Variable & $\begin{array}{l}\text { Risk ratio } \\
(95 \% \text { confidence interval) }\end{array}$ & $p$ Value \\
\hline \multicolumn{3}{|l|}{ Univariate analysis } \\
\hline Age at Mustard operation, years & - & 0.15 \\
\hline Male & - & 0.76 \\
\hline "Complex" Mustard & - & 0.90 \\
\hline NYHA $\geqslant$ III & - & 0.53 \\
\hline Superior QRS axis & - & 0.64 \\
\hline QRS duration max (ms) & - & 0.06 \\
\hline QT dispersion (ms) & $1.02(1.00$ to 1.04$)$ & 0.002 \\
\hline U wave & $4.27(1.05$ to 17.30$)$ & 0.04 \\
\hline Junctional rhythm & - & 0.57 \\
\hline RV dysfunction $\geqslant$ III and TR $\geqslant I I I$ & $3.68(1.05$ to 12.88$)$ & 0.04 \\
\hline $\mathrm{LV}$ hypertension $(\geqslant 60 \mathrm{~mm} \mathrm{Hg})$ & - & 0.30 \\
\hline RVEDD on MRI (mm) & - & 0.06 \\
\hline LVEDD on MRI (mm) & $0.90(0.82$ to 0.99$)$ & 0.04 \\
\hline RVEDD/LVEDD on MRI & $2.25(1.16$ to 4.34$)$ & 0.01 \\
\hline RVEF, rest RNA (\%) & - & 0.12 \\
\hline RVEF, exercise RNA (\%) & $0.94(0.90$ to 0.99$)$ & 0.03 \\
\hline Exercise time (min) & - & 0.27 \\
\hline Anaerobic threshold (ml/kg/min) & - & 0.36 \\
\hline$\dot{\mathrm{V}}_{2} \max (\mathrm{ml} / \mathrm{kg} / \mathrm{min})$ & - & 0.21 \\
\hline Work load (kpm) & $0.99(0.98$ to 1.00$)$ & 0.04 \\
\hline \multicolumn{3}{|l|}{ Multivariate analysis } \\
\hline QT dispersion (ms) & $1.04(1.00$ to 1.08$)$ & 0.02 \\
\hline
\end{tabular}

LV, left ventricular; LVEDD, left ventricular end diastolic diameter; MRI, magnetic resonance imaging; NYHA, New York Heart Association functional class; RNA, radionuclide angiography; $\mathrm{RV}$, right ventricular; RVEDD, right ventricular end diastolic diameter; RVEF, right ventricular ejection fraction.

\section{Discussion}

We have shown that late clinical arrhythmia in patients with the Mustard procedure for transposition of great arteries relates to impaired systemic right ventricular function.

Our radionuclide angiographic data reinforce previous studies showing systemic right ventricular dysfunction in patients undergoing the Mustard procedure for transposition of great arteries..$^{4518}$ Many of our adult patients were asymptomatic at follow up. However, during exercise stress, their cardiac limitations became apparent, as manifested by their decreased maximum workload, diminished anaerobic threshold and $\dot{\mathrm{V}}_{2} \max$, and lower systemic ventricular ejection fraction. ${ }^{19-21}$ Maximum oxygen uptake of $17.5 \mathrm{ml} / \mathrm{kg} / \mathrm{min}$ at a mean of 23.4 years after the Mustard procedure in our adult cohort was significantly lower than the mean of $27 \mathrm{ml} / \mathrm{kg} / \mathrm{min}$ at 10.3 years after Mustard operation in a report on young adolescents. ${ }^{22}$ Right ventricular ejection fraction from the present series, both at rest $(44.5 \%)$ and during exercise $(49.3 \%)$, was also lower than in a previous report by Hochreiter and colleagues (right ventricular ejection fraction $52 \%$ at rest and $56 \%$ during exercise) at a mean of 17.8 years after the Mustard procedure. ${ }^{23}$ These differences in systemic ventricular function and cardiopulmonary performance may reflect the longer period of follow up after the Mustard procedure in our older patients.

Late clinical arrhythmia in this study $(21.5 \%)$ consisted predominantly of atrial flutter/fibrillation and was more common than in two recent reports by Gewillig and colleagues $(16 \%)^{1}$ and Gelatt and associates $(14 \%) .{ }^{2}$ Again, the longer follow up time in our study may account for this difference (mean follow up 23.4 years after the Mustard procedure $v 11.7$ and 11.6 years in the studies by Gewillig and Gelatt, respectively). Whereas cardiac enlargement on chest radiography was seen in the overall population, there was no significant difference in right ventricular end diastolic dimension between the patients with arrhythmia and the remainder. However, left ventricular end diastolic dimension was significantly smaller in the arrhythmia subgroup; this, combined with the normal left ventricular function in both subgroups and the higher ratio of RVEDD/LVEDD in the arrhythmia subset, is consistent with a ventriculo-ventricular interaction $^{24}$ and may suggest relative right ventricular enlargement. The longer QRS duration in the arrhythmia subgroup, which in turn correlated with right ventricular end diastolic dimension on magnetic resonance imaging, would also support this theory. There was no difference between absolute or relative (to the left) right ventricular free wall thickness between the arrhythmia patients and the remainder. This suggests that right ventricular hypertrophic response to chronic pressure overload - or its absence-may not be responsible for arrhythmogenesis in these patients, at least in isolation. This concurs with the earlier report by Lorenz and colleagues, ${ }^{25}$ in which "inadequate" right ventricular hypertrophy did 
not appear to be the cause of late dysfunction in 22 patients assessed by magnetic resonance imaging after atrial switch procedures. The severity of tricuspid regurgitation assessed echocardiographically was not significantly greater in the arrhythmia subgroup. Likewise, closure of ventricular septal defect or relief of left ventricular outflow tract obstruction at the time of the Mustard procedure was not an independent predictor of late arrhythmia. The combination of tricuspid regurgitation with right ventricular dysfunction, however, was more common in the arrhythmia patients. This finding contrasts with the recent report by Gelatt and colleagues, ${ }^{2}$ in which damage to the tricuspid valve during ventricular septal defect closure was postulated as a causative mechanism of atrial flutter and sudden death. Our data suggest that tricuspid regurgitation may rather be the result of progressive right ventricular dysfunction and ensuing annular dilatation, and not secondary to iatrogenic factors. Different lengths of follow up between the two studies may explain this discrepancy.

Despite the common arrhythmogenic substrate, namely previous intra-atrial surgery and the presence of intra-atrial baffles, ${ }^{26}{ }^{27}$ not all patients after the Mustard procedure develop late clinical arrhythmia. An additional factor, or factors, seems to be required for arrhythmogenesis. Our data suggest that a greater degree of right ventricular dysfunction, as expressed by the lower right ventricular ejection fraction in the arrhythmia subset (compared with the arrhythmia-free patients), is a contributory factor in initiating or sustaining the arrhythmia, and in turn leads to haemodynamic compromise. This is purely speculative, but it needs to be determined whether ACE inhibitors have a positive effect on right ventricular function and in turn on the incidence of late arrhythmia in this population. ${ }^{28}$

QT dispersion on the surface ECG, a marker of ventricular inhomogeneity more frequently reported in groups susceptible to ventricular tachycardia, ${ }^{139-32}$ was also significantly greater in the arrhythmia subgroup and predictive of late arrhythmia. This pronounced QT dispersion, seen in patients who went on to develop predominantly atrial flutter/fibrillation, can be taken as further evidence that ventricular dysfunction is a contributory factor in this population predisposed to atrial arrhythmia. ${ }^{33}$ Furthermore, it suggests that these patients may also be at risk of ventricular tachycardia. This was indeed the case with one of our patients. Although sustained ventricular tachycardia has not been widely reported in Mustard cohorts, we speculate that with increasing length of follow up and the anticipated progression of right ventricular dysfunction in a subset of adult patients, this will become an increasing problem in the future.

Sudden death, presumably arrhythmic, has been reported in all large series..$^{1-3}$ As with atrial flutter, it has been postulated that sudden death relates to right ventricular dysfunction. Complete atrioventricular block, atrial flutter with one to one atrioventricular conduction, and sustained ventricular tachycardia degener- ating to ventricular fibrillation are all potential causes. Its precise mechanism, however, remains unknown. Only one of our patients died. This was the patient with ventricular tachycardia and end stage heart failure, who died from myocardial standstill during heart transplantation. There is a clear need to identify patients at risk of sudden death. Our study cannot answer this question, as none of the patients with atrial flutter/fibrillation died. Nevertheless it provides evidence of the presence of a mechanoelectric interaction in patients with Mustard procedure for transposition of great arteries. Impaired systemic ventricular function in these adult patients is associated with late clinical arrhythmia. At a mean of 23 years after the Mustard procedure this arrhythmia was predominantly atrial flutter/fibrillation.

\section{LIMITATIONS}

We have not specifically addressed the diastolic function of the systemic and pulmonary ventricles, which may be equally important, both in terms of cardiopulmonary exercise performance and arrhythmogenesis. Volumetric data derived from cine magnetic resonance imaging were not always available and hence were not included in the analysis. Additional predictors of late arrhythmia may exist and could be identified with a larger patient sample and a longer period of observation in future studies.

\section{CONCLUSIONS}

We conclude that impaired systemic ventricular function in adult patients late after the Mustard procedure for transposition of great arteries relates to clinical arrhythmia. Atrial flutter/fibrillation may be a surrogate marker for ventricular dysfunction in this population. Adult patients presenting with late atrial tachyarrhythmia after the Mustard procedure may also be at risk of ventricular tachycardia.

We thank our colleagues form The Hospital for Sick Children for their continuing support of the University of Toronto Congenital Cardiac Centre for Adults programme. MAG was supported in part by a 1997 University of Toronto, Department of Medicine postgraduate fellowship award. PL is a recipient of of Medicine, postgraduate fellowship award. PL is a recipient of a research chair of the Heart and Stroke Foundation of Ontario and was supported in part by a grant from the Heart and Stroke

1 Gewillig M, Cullen S, Mertens B, et al. Risk factors for arrhythmia and death after Mustard operation for simple ransposition of the great arteries Circulation 1991;84(suppl III):III-187-92.

2 Gelatt M, Hamilton RM, McCrindle BW, et al. Arrhythmia and mortality after the Mustard procedure: a 30-year single-center experience. $\mathcal{f} \mathrm{Am}$ Coll Cardiol 1997;29:194201 .

3 Flinn CJ, Wolff GS, Dick M, et al. Cardiac rhythm after the Mustard operation for complete transposition of the great Mustard operation for complete transpositi
arteries. N Engl f Med 1984;310:1635-8.

4 Benson LN, Bonet J, McLaughlin P, et al. Assessment of right ventricular function during supine bicycle exercise after Mustard's operation. Circulation 1982;65:1052-9.

5 Hurwitz RA, Caldwell RL, Girod DA, et al. Right ventricular systolic function in adolescents and young adults after Mustard operation for transposition of the great arteries. Am f Cardiol 1996;77:294-7.

6 Cochrane AD, Karl TR, Mee RBB. Staged conversion to arterial switch for late failure of the systemic right ventricle. Ann Thorac Surg 1993;56:854-62.

7 Chang AC, Wernovky G, Wessel DL, et al. Surgical management of late right ventricular failure after Mustard or Senning repair. Circulation 1992;86(suppl II):II-140-9.

8 Van Son JA, Reddy VM, Silverman NH, et al. Regression of tricuspid regurgitation after two-stage arterial switch operation for failing systemic ventricle after atrial inversion operation. F Thorac Cardiovasc Surg 1996;111:342-7.

9 Jatene AD, Fontes VF, Souza LC, et al. Anatomic correction of transposition of the great vessels. $\mathcal{F}$ Thorac Cardiovasc Surg 1982;83:20-6. 
10 Yacoub MH, Radley-Smith R, Hilton CJ. Anatomical correction of complete transposition of the great arteries and vention of complete transposition of the great arteries and
tricular septal defect in infancy. BMF 1976;i:1112-14.

11 Perloff JK. Congenital heart disease in adults: a new cardiovascular specialty. Circulation 1991;84:1881-90.

12 Gatzoulis MA, Till JA, Somerville J, et al. Mechanoelectrical interaction in tetralogy of Fallot: QRS prolongation relates to right ventricular size and predicts malignant ventricular arrhythmias and sudden death. Circulation 1995;92:231-7

13 Gatzoulis MA, Till JA, Redington AN. Depolarisationrepolarisation inhomogeneity after repair of tetralogy of Fallot: the substrate for malignant ventricular tachycardia? Circulation 1997;95:401-4.

14 Guit GL, Bluemm R, Rohmer J, et al. Levotransposition of the aorta: identification of segmental cardiac anatomy using MR imaging. Radiology 1986;161:673-9.

15 Pavel DG, Zimmer AM, Patterson VN. In vivo labeling of red blood cells with ${ }^{99} \mathrm{Tc}$ : a new approach of blood pool red blood cells with Tc: a new approach

16 Harrison DA, Liu P, Walters JE, et al. Cardiopulmonary function in adult patients late after Fontan repair. $\mathcal{F}$ Am Coll function in adult patients

17 Cox DR. Regression models and life tables. F R Stat Soc (B) 1972:34:187-220.

18 Redington AN, Rigby ML, Oldershaw P, et al. Right ventricular function 10 years after the Mustard operation for transposition of the great arteries: analysis of size, shape, and wall motion. Br Heart $\mathcal{F} 1989 ; 62: 455-61$.

19 Musewe NN, Reisman J, Benson LN, et al. Cardiopulmonary adaptation at rest and during exercise 10 years after Mustard atrial repair for transposition of the great arteries. Circulation 1988;77:1055-61.

20 Bowyer JJ, Busst CM, Till JA, et al. Exercise ability after Mustard's operation. Arch Dis Child 1990;65:865-70.

21 Reybrouck T, Gewillig M, Dumoulin M, et al. Cardiorespiratory exercise performance after Senning operation for ratory exercise performance after Senning operation for 9.

22 Ensin

nsing GJ, Heise CT, Driscoll DJ. Cardiovascular response to exercise after the Mustard operation for simple and complex transposition of the great vessels. Am $\mathcal{f}$ Cardiol $1988 ; 62: 617-22$

23 Hochreiter C, Snyder MS, Borer JS, et al. Right and left ventricular performance 10 years after Mustard repair of transposition of the great arteries. Am F Cardiol 1994;74: 478-82.

24 Fogel MA, Weinberg PM, Fellows KE, et al. A study in ventricular-ventricular interaction: Single right ventricles compared with systemic right ventricles in a dual-chamber circulation. Circulation 1995;92:219-30.

25 Lorenz CH, Walker ES, Graham TP, et al. Right ventricular performance and mass by use of cine magnetic resonance imaging late after atrial repair of transposition of the great arteries. Circulation 1995;92 (suppl II):II-233-9.

26 El-Said G, Rosenberg HS, Mullins CE, et al. Dysrrhythmias after Mustard's operation for transposition of the great arteries. Am f Cardiol 1972;30:526-32.

27 Gillette PC, El-Said GM, Sivarajan N, et al. Electrophysiological abnormalities after Mustard's operation for transposition of the great arteries. Br Heart f 1974;36:186-91.

28 Pedersen OD, Bagger H, Kober L, et al, for TRACE. Trandopril reduces the incidence of atrial fibrillation after acute myocardial infarction in patients with left ventricular dysfunction. Circulation 1999;100:376-80.

29 Day CP, McComb JM, Campbell RWF. QT dispersion: an indication of arrhythmia in risk patients with long QT intervals. Br Heart F. 1990;63:342-4.

30 Buja G, Miorelli M, Turrini P, et al. Comparison of QT dispersion in hypertrophic cardiomyopathy between patients with and without ventricular arrhythmias and sudden death. Am f Cardiol 1993;72:973-6.

31 Barr CS, Naas A, Freeman M, et al. QT dispersion and sudden unexpected death in chronic heart failure. Lancet 1994;343:327-9.

32 Fu GS, Meissner A, Simon R. Repolarization dispersion and sudden cardiac death in patients with impaired left ventricular function. Eur Heart f 1997; 18:281-9.

33 Dean JW, Lab MJ. Arrhythmia in heart failure: role of mechanically induced changes in electrophysiology. Lancet 1989;i:1309-11.

\section{IMAGES IN CARDIOLOGY}

\section{UPO: unidentified pericardial object}
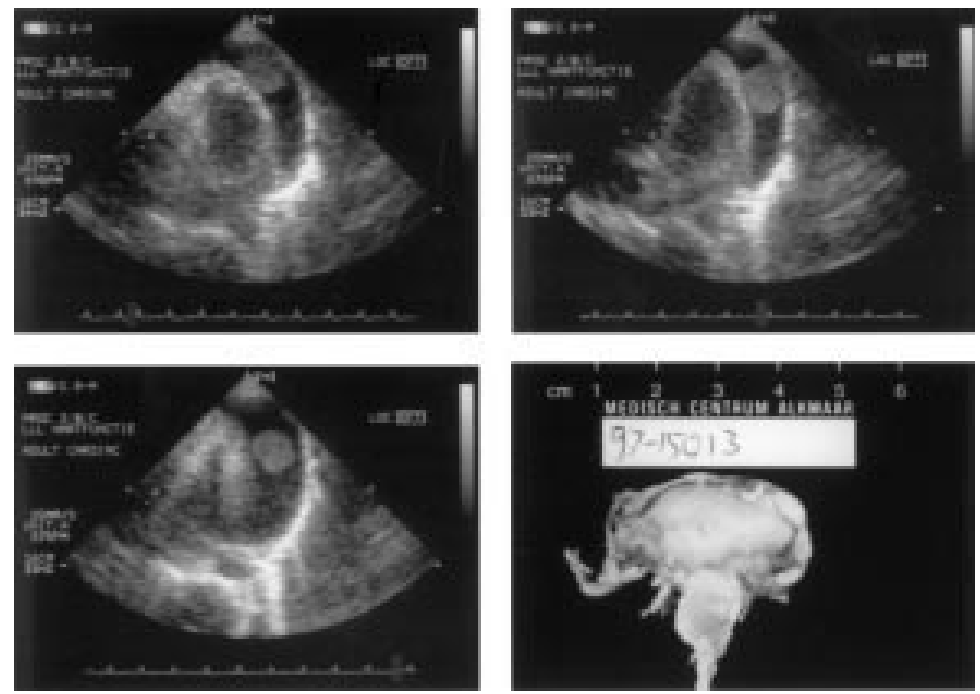

A 54 year old woman was admitted to our hospital because of severe chest pain and progressive dyspnoea. Physical examination revealed hypotension, elevated central venous pressure, and a loud triphasic myocardial friction rub. Echocardiography showed a large amount of pericardial fluid compressing the heart and a round structure freely floating in the pericardial fluid. The apex of the heart moved the mass like the nose of a seal that plays a ball. Because of haemodynamic failure lateral thoracotomy with partial pericardiectomy was performed. About $700 \mathrm{ml}$ of fluid and the unidentified pericardial object were removed. Histopathological examination revealed signs of an aspecific chronic fibrinous exudative pericarditis, and the structure was pure fibrin in origin. Cultures and serological study yielded no evidence of a causative organism. The patient made a quick and full recovery and returned to work.

JOLANDE BOLK CONSTANT L A REICHERT 